\title{
Therapeutic prospects of metabolically active brown adipose tissue in humans
}

\author{
Matthias J. Betz ${ }^{1,2}$ and Sven Enerbäck ${ }^{1 *}$ \\ ${ }^{1}$ Department of Medical Genetics, Institute of Biomedicine, Sahlgrenska Academy, University of Göteborg, Göteborg, Sweden \\ ${ }^{2}$ Medizinische Klinik, Campus Innenstadt, Klinikum der Ludwig-Maximilians-Universität München, Munich, Germany
}

\author{
Edited by: \\ Patrick Seale, University of \\ Pennsylvania, USA \\ Reviewed by: \\ Darlene Evans Berryman, Ohio \\ University, USA \\ Vincenzo Carlo Russo, Murdoch \\ Childrens Research Institute, Australia \\ *Correspondence: \\ Sven Enerbäck, Department of \\ Medical Genetics, Institute of \\ Biomedicine, Sahlgrenska Academy, \\ University of Göteborg, \\ Medicinaregatan 9A, Box 440, \\ Göteborg 40530, Sweden. \\ e-mail: sven.enerback@medgen.gu.se
}

The world-wide obesity epidemic constitutes a severe threat to human health and wellbeing and poses a major challenge to health-care systems. Current therapeutic approaches, relying mainly on reduced energy intake and/or increased exercise energy expenditure, are generally of limited effectiveness. Previously believed to be present only in children, the existence of metabolically active brown adipose tissue (BAT) was recently demonstrated also in healthy human adults. The physiological role of BAT is to dissipate chemical energy, mainly from fatty acids, as heat to maintain body temperature in cold environments. Recent studies indicate that the activity of BAT is negatively correlated with overweight and obesity, findings that raise the exciting possibility of new and effective weight reduction therapies based on increased BAT energy expenditure, a process likely to be amenable to pharmacological intervention.

Keywords: brown adipose tissue, thermogenesis, energy expenditure, obesity, overweight, weight loss, metabolic syndrome

\section{INTRODUCTION}

The prevalence of overweight and obesity has increased worldwide during the recent decades, constituting a severe threat to public health and causing enormous health-care costs. Obesity is a major risk factor for type II diabetes mellitus, cardiovascular disease, osteoarthritis, and certain forms of cancer (Haslam and James, 2005), ultimately leading to increased mortality (Pischon et al., 2008; Berrington De Gonzalez et al., 2010; Zheng et al., 2011). The causes of obesity are complex in terms of physiology, but are quite straightforward in terms of physics: obesity stems from a long-term imbalance of energy intake and energy expenditure. While lipid deposition in adipose tissue is a normal and vital physiologic process not necessarily causing disease, excess triglyceride accumulation strains the capacity of adipose depots and often leads to ectopic lipid deposition in skeletal muscle and liver. This perturbs a multitude of metabolic pathways, which leads to insulin resistance and type II diabetes mellitus (Qatanani and Lazar, 2007).

Fortunately, the adverse metabolic consequences of obesity can be reversed by weight loss (Petersen et al., 2005). However, this is often difficult to achieve with currently available therapies.

\section{LIMITATIONS OF CURRENT THERAPIES AGAINST OBESITY}

Presently, the only scientifically proven, effective therapy of morbid obesity, both in terms of weight loss and decreased morbidity and mortality, is bariatric surgery (Sjostrom et al., 2004, 2007; Adams

Abbreviations: BAT, brown adipose tissue; $\mathrm{BMR}$, basal metabolic rate; $\mathrm{DIO}$, type 2 deiodinase; FDG PET-CT, ${ }^{18} \mathrm{~F}$-fluorodeoxyglucose positron emission tomography combined with computed tomography; FGF, fibroblast growth factor; SNS, sympathetic nervous system; THR, thyroid hormone receptor; UCP1, uncoupling protein 1 ; WAT, white adipose tissue. et al., 2007). However, this therapeutic approach is invasive and it is available only to a subgroup of morbidly obese subjects.

A mainstay of current medical management of overweight and obesity is caloric restriction, i.e., limiting the amount of calories ingested to a level below the patient's estimated or measured total energy expenditure (Eckel, 2008). While this may seem to be the most logical approach, it faces several obstacles: the sensation of hunger is recognized as very unpleasant and drugs acting on the CNS to suppress appetite such as Sibutramine or Rimonabant can cause serious adverse events. Use of sibutramine, a substance targeting the central monoamine system, was associated with increased incidence of non-fatal myocardial infarction and stroke (James et al., 2010), which led to its withdrawal. Another promising appetite suppressant, Rimonabant, a cannabinoid receptor 1 blocker that was effective in inducing and maintaining weight loss as well as improving insulin sensitivity, failed to get approval from the Federal Drug Administration in the United States and was withdrawn in Europe due to increased incidence of depression and suicide (Christensen et al., 2007).

Additionally, caloric restriction as the sole method of weight reduction is accompanied by both metabolic and behavioral compensations leading to reduced basal metabolic rate (BMR) and reduced physical activity level (Martin et al., 2007). These adaptations commonly lead to unwanted weight regain, often predominantly as fat mass, once the caloric restriction ends (Dulloo et al., 1997).

In comparison these compensatory changes were not observed in a combination therapy of caloric restriction and exercise (Redman et al., 2009). This is in line with results from other studies, identifying energy expenditure through physical activity as a main determinant of successful weight reduction and long-term weight control (Wing and Hill, 2001; Weinsier et al., 2002). Moreover, a 
combination of caloric restriction and structured exercise led to greater weight loss and a more favorable cardio-metabolic profile (Goodpaster et al., 2010). Unfortunately, increasing physical activity often proves difficult for obese patients due to musculoskeletal and cardiovascular disease, causing a vicious circle of reduced exercise, reduced energy expenditure, increased body weight and even further reduced activity. Alternative ways to increase energy expenditure could expand the therapeutic options for treating obese patients and ultimately lead to more successful treatment.

\section{BROWN ADIPOSE TISSUE BROWN ADIPOSE TISSUE PHYSIOLOGY}

Adipose tissue exists in two distinct forms: white adipose tissue (WAT) and brown adipose tissue (BAT). WAT is the main energy storage compartment of the mammalian body. It is characterized by adipocytes containing a single large lipid droplet storing excess energy in the form of triglycerides. White adipocytes possess relatively few mitochondria and a peripherally located nucleus. In addition, WAT constitutes a large endocrine organ that secretes hormones such as leptin and adiponectin which are involved in the regulation of satiety and insulin sensitivity (Kershaw and Flier, 2004). BAT is a densely innervated and highly perfused tissue consisting of brown adipocytes, a cell type characterized by small multilocular lipids droplets, a central nucleus, and a high number of mitochondria. The major differences between WAT and BAT are summarized in Table 1.

Within the mitochondrial matrix acetyl-CoA derived from carbohydrates, fatty acids, or proteins is fed into the citric acid cycle. The chemical energy released by the stepwise oxidation of acetylCoA is then transferred to the electron transport chain in the inner mitochondrial membrane building up a proton gradient across the membrane. Usually, the flow of protons back to the mitochondrial matrix through a channel in the ATP-synthase complex powers the synthesis of ATP (Berg et al., 2007), thereby coupling the oxidation of nutrients to the generation of the cell's energy currency. Brown adipocytes are unique in their expression of UCP1, the gene encoding uncoupling protein 1. Activation of UCP1 short-circuits or uncouples the proton gradient from ATP generation, thereby dissipating the energy stored in the gradient as heat (Figure 1A).

Table 1 | Characteristic of white vs. brown adipose tissue.

\begin{tabular}{ll}
\hline White adipose tissue & Brown adipose tissue \\
\hline $\begin{array}{l}\text { White adipocytes contain } \\
\text { single large lipid droplet, few } \\
\text { mitochondria }\end{array}$ & $\begin{array}{l}\text { Brown adipocytes contain multiple small } \\
\text { lipid droplets, rich in mitochondria }\end{array}$ \\
$\begin{array}{l}\text { Secretes adipose derived } \\
\text { hormones, that regulate }\end{array}$ & $\begin{array}{l}\text { Densely vascularized and innervated by } \\
\text { insulin sensitivity and satiety } \\
\text { Stores excess energy as } \\
\text { triglycerides, releases fatty }\end{array}$ \\
acids during fasting periods & Expression of uncoupling protein 1 \\
&
\end{tabular}

fatty acids) to generate heat
The physiological function of BAT is thus to convert chemical energy, mainly from lipids, into thermal energy. This capability is very important for small and hibernating mammals as well as for newborn humans to maintain body temperature in cold environments. In the mammalian body heat is generated as a by-product of basic cellular and organ functions (BMR), of digestion and absorption of food, and of voluntary and involuntary movement. If this amount of thermal energy does not suffice to keep the body temperature within the normal range in a cold environment, adaptive thermogenesis sets in. Even before core body temperature drops cold is sensed by receptors in the skin. The afferent information is integrated in the hypothalamus leading to disinhibition of its thermogenesis-promoting neurons, which in turn increases sympathetic output to BAT (Nakamura and Morrison, 2007). Acute cold stress in non-cold adapted animals causes muscle shivering as a first mechanism to defend body temperature. During chronic cold exposure the amount of shivering abates over the course of days to weeks as non-shivering thermogenesis increases (Cannon and Nedergaard, 2004). The signal from the sympathetic nervous system (SNS) is relayed by noradrenergic neurons, which stimulate G-protein coupled $\beta 3$-adrenoreceptors ( $\beta 3$-AR) in BAT. Stimulation of $\beta 3$-ARs leads to lipolysis via activation of the $\mathrm{G}_{\mathrm{s}}$-adenylyl cyclase-PKA pathway. The fatty acids released by lipolysis do not only represent the main substrate of thermogenesis, but they also activate UCP1 allosterically (Figure 1B; Cannon and Nedergaard, 2004).

Thyroid hormone is an important endocrine modulator of thermogenesis. It potentiates the actions of catecholamines on the $\beta 3$-AR and adenylyl cyclase and increases the transcription of UCP1 through thyroid hormone receptor (THR) response elements located in the UCP1 promoter (Silva and Rabelo, 1997). Moreover, BAT expresses high levels of type 2 iodothyronine deiodinase (DIO2), an enzyme converting tetraiodothyronine $\left(\mathrm{T}_{4}\right)$ into the active triiodothyronine $\left(\mathrm{T}_{3}\right)$. Type 1 iodothyronine deiodinase (DIO1) is mainly expressed in liver and kidney and is the main source of plasma $\mathrm{T}_{3}$ in hyperthyroid patients. While DIO1 is under tight transcriptional control of thyroid hormones, DIO2 expression is induced by catecholamines acting through the cAMP signaling cascade. Its effects in promoting $\mathrm{T}_{3}$ production are limited to BAT and do not affect plasma $\mathrm{T}_{3}$ levels (Bianco and Kim, 2006).

About 30 years ago Rothwell and Stock described that ad libitum feeding of a high calorie diet rich in fat and carbohydrates, casually dubbed "cafeteria diet," led to recruitment and activation of BAT in rats and thus increased energy expenditure. They concluded that BAT was a major site of diet induced thermogenesis (DIT), the increase in energy expenditure that follows food intake and might thus protect against diet induced obesity (Rothwell and Stock, 1979). In contrast to cold-induced thermogenesis, which is generally undisputed, the proposal of DIT as a function of BAT is more controversial (Kozak, 2010; Fromme and Klingenspor, 2011).

\section{ORIGINS AND DIFFERENTIATION OF BROWN ADIPOSE TISSUE}

In contrast to earlier assumptions of a common origin of brown and white adipocytes, recent research clearly demonstrates that brown and white adipocytes have distinct developmental origins. 


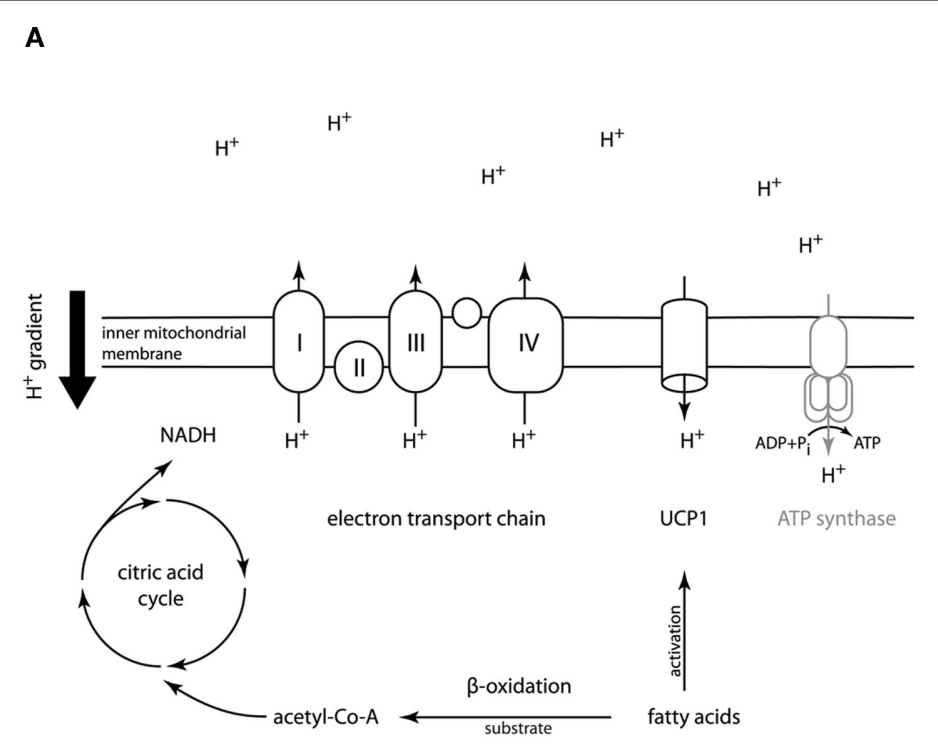

B
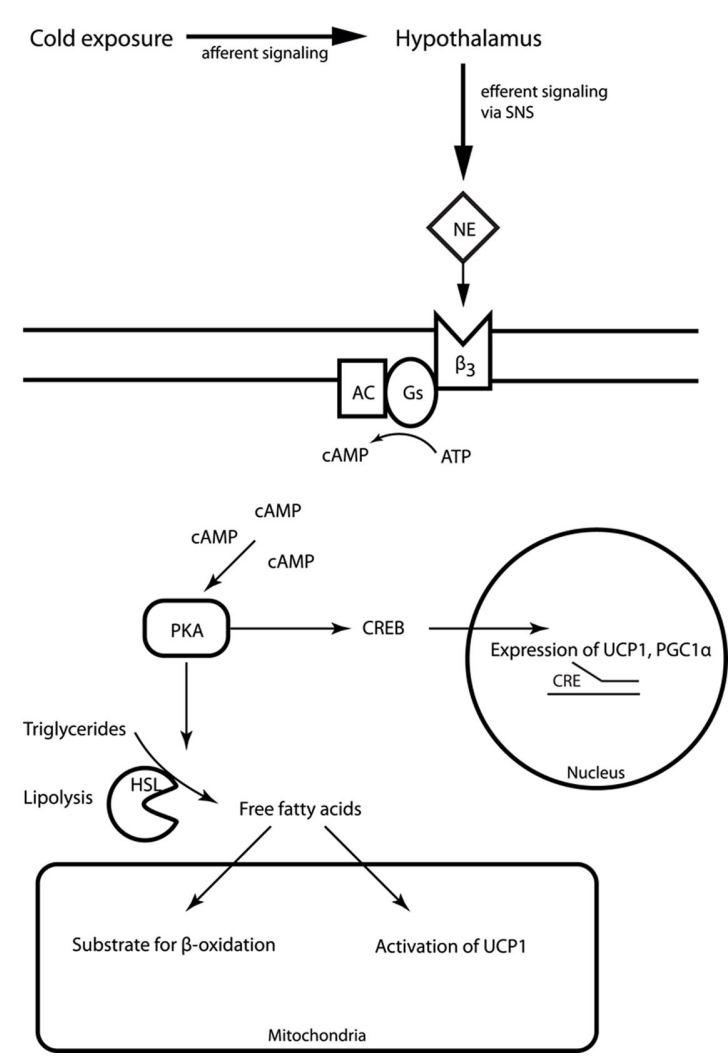

FIGURE 1 | (A) Outline of UCP1 action in brown adipocyte mitochondria. The electron transport chain generates a proton gradient across the inner mitochondrial membrane. This electromotive force is usually drives ATP-synthase restoring the cell's energy currency ATP. Activation of UCP1 by fatty acids in brown adipocytes dissipates the proton gradient without coupling to ATP regeneration releasing the energy as heat. (Details of the electron transport chain have been omitted for reasons of simplicity). (B) Outline of BAT regulation. Upon cold exposure afferent signals from cold receptors are integrated in the hypothalamus. The efferent signal is transmitted via the sympathetic nervous system (SNS) and norepinephrine (NE) acting on the $\beta_{3}$-adrenoreceptor located on the brown adipocyte surface, which is coupled to the cAMP second messenger pathway. Phosphorylation of hormone sensitive lipase and perilipin activates lipolysis. The resulting free fatty acids provide the fuel for thermogenesis and activate UCP1 allosterically. Additionally, transcription of UCP1 and PGC-1 $\alpha$ is activated via the CREB/CRE pathway.
Atit et al. (2006) proposed a common origin of skeletal muscle and BAT, based on their finding that specific cells of the dermomyotome positive for the transcription factor engrailed-1 develop into both skeletal myocytes and brown, but not white adipocytes. In parallel with this finding, lineage tracing revealed that both brown adipocytes located in the interscapular BAT and myocytes derive from precursors positive for the myogenic transcription factor Myf5 (Timmons et al., 2007).

Seale et al. (2008) delineated the existence of two different types of brown adipocytes: those found in "classic" BAT (e.g., interscapular BAT), deriving from $M y f 5$ positive precursors, and a second population, deriving from $M y f 5$ negative precursors, that is interspersed in WAT. Because these interspersed brown adipocytes appear upon stimulation with cold or $\beta 3$-AR agonists, we chose to call them "recruitable" brown adipocytes to discriminate them from the invariably present "classic" brown adipocytes, which are located in typical BAT fat pads.

Our knowledge of BAT development and differentiation has advanced considerably during recent years, as several transcriptional regulators essential to BAT have been discovered.
PPAR $\gamma$ coactivator- $1 \alpha$ (PGC- $1 \alpha)$ is highly induced in BAT upon cold exposure, mediated via SNS stimulation and the cAMPPKA second messenger pathway. It interacts with PPAR $\gamma$ and is an important regulator of mitochondrial biogenesis and oxidative phosphorylation. Ectopic overexpression of PGC- $1 \alpha$ in white adipocytes induces UCP1 and other thermogenic genes, while its genetic ablation severely reduces the animals' capacity for adaptive thermogenesis (Seale et al., 2009). The importance of the cAMPPKA pathway for brown adipocyte development is highlighted by the fact that FOXC2, a member of the forkhead transcription factor family, sensitized adipocytes to the actions of $\beta 3$-AR agonists by inducing the expression of the RI $\alpha$ subunit of PKA (Cederberg et al., 2001; Dahle et al., 2002). Overexpression of FOXC2 in adipose tissue led to a "browning" of white fat pads and protected mice against diet induced obesity and insulin resistance.

In conjunction with the discovery of a common lineage of BAT and muscle PRDM16 was identified as a molecular switch between brown adipocyte and myocyte development. Ectopic expression of PRDM16 in myoblasts induced differentiation into brown adipocytes possessing the full molecular machinery necessary for 
thermogenesis. In contrast, loss of PRDM16 in BAT pre-cursor cells led to a loss of the brown adipocyte phenotype and myocyte differentiation (Seale et al., 2008). When PRDM16 was transgenically expressed in the subcutaneous WAT of mice, brown adipocyte like cells appeared in this fat pad, rendering the mice less obesity prone and more glucose tolerant (Seale et al., 2011).

\section{IMPLICATIONS OF BAT IN METABOLISM AND BODY WEIGHT IN RODENTS}

During the last three decades the effects of active BAT on body weight and metabolism in rodents have been carefully studied.

Several different models of BAT disruption clearly demonstrated its importance for adaptive thermogenesis and also highlighted its relevance for body weight regulation. Surgical denervation or excision of BAT in mice led to increased body weight as compared with sham operated animals (Dulloo and Miller, 1984). Biochemical disruption of BAT by expression of cholera toxin A under the control of the UCP1 promoter induced obesity and insulin resistance in mice (Lowell et al., 1993). A complete knock-out of the UCP1 gene did, somewhat unexpectedly, not result in obesity, when mice were housed at usual animal facility temperatures (i.e., around $22^{\circ} \mathrm{C}$; Enerback et al., 1997). However, keeping them at conditions of thermoneutrality (i.e., $30-33^{\circ} \mathrm{C}$ for mice) rendered the animals obese (Feldmann et al., 2009).

Expansion of BAT on the other hand resulted in opposite effects on body weight and metabolism. Transgenic mice overexpressing UCP1 in WAT displayed a reduced amount of subcutaneous fat at 3 months of age and when the transgene was expressed in a genetically obese mouse strain, it protected against obesity (Kopecky et al., 1995). Overexpression of the forkhead transcription factor FOXC2 in adipose tissue led to a "browning" of WAT fat pads, with expression of UCP1 and increased vascularization. Accordingly, the animals were protected from diet induced obesity, as well as insulin resistance and hypertriglyceridemia (Cederberg et al., 2001; Kim et al., 2005).

Pharmacological stimulation of the $\beta 3$-adrenoreceptor ( $\beta 3$ AR) with the specific agonist CL316,243 in Zucker fa/fa rats led to the appearance of brown adipocytes in WAT regions, increased $\mathrm{BMR}$, and reversed diet induced obesity. Upon treatment with the agonist obese rats showed a more pronounced increase of BMR than lean controls and partial reversion of hyperphagia, while food intake remained constant in lean controls. Additionally, the hyperinsulinemia and hyperglycemia of the Zucker fa/fa rats was ameliorated, indicating reduced insulin resistance (Ghorbani and Himms-Hagen, 1997).

Similar experiments were performed in mice. However, the ability of $\beta 3$-AR agonists to induce brown adipocytes in WAT regions varied enormously between different mouse strains, as did the body weight after high fat feeding. Importantly, the variation of UCP1 expression in the classic interscapular BAT fat pad was rather small between the different mouse strains, indicating that the differences in body weight were largely conferred by recruitable brown adipocytes in WAT regions (Collins et al., 1997; Guerra et al., 1998). This genetic variability of UCP1 expression in different adipose tissue compartments could not be explained by variation in the expression of specific transcription factors, but rather suggests different developmental mechanisms for the two brown adipocyte populations (Xue et al., 2007).

Bartelt et al. investigated the implications of BAT activation on lipid metabolism. They demonstrated that clearance of triglyceride-rich lipoproteins from plasma in BAT drastically increased upon short-term cold exposure thus correcting hyperlipidemia and ameliorating insulin resistance in mice (Bartelt et al., 2011). As hyperlipidemia is a leading risk factor for cardiovascular disease, the authors speculated that activation of BAT might be a valuable therapeutic approach to correct hypertriglyceridemia and associated diseases in humans.

In conclusion, in rodents an impressive amount of scientific evidence highlights the beneficial consequences of active BAT for regulation of normal body weight, insulin sensitivity, and lipid metabolism. Given the implications of these findings, BAT had already been considered an attractive therapeutic target in humans suffering from overweight and obesity decades ago. However, the recent proof of its presence and activity in human adults has sparked new interest in this possibility.

\section{BROWN ADIPOSE TISSUE IN HUMANS EVIDENCE AND PREVALENCE OF ACTIVE BAT IN HUMAN ADULTS}

While the existence of BAT in rodents and human infants has been known for decades and its physiological function was described as early as the 1960s, it was only recently that several researchers could unequivocally identify active BAT in human adults using

${ }^{18} \mathrm{~F}$-fluorodeoxyglucose positron emission tomography combined with computed tomography (FDG PET-CT; Cypess et al., 2009; Van Marken Lichtenbelt et al., 2009; Virtanen et al., 2009). For a summary of recent studies investigating BAT in humans see Table 2.

The FDG PET-CT is currently the only imaging technique that can visualize active BAT. Due to the ionizing radiation associated with its use, it has up to now not been possible to conduct large studies in healthy individuals to test for the presence of active BAT. Instead researchers have often made use of already available FDG PET-CT scans, most commonly obtained during routine diagnostic studies for staging of cancer. The total proportion of subjects displaying active BAT in these studies was relatively low, generally below 10\% (Cypess et al., 2009; Jacene et al., 2011; Ouellet et al., 2011).

Using BAT as a therapeutic target to combat obesity and associated diseases does, however, only make sense, if it is present in the vast majority of patients and not just an occasional remnant of BAT present at birth. While the data obtained from cross-sectional retrospective analysis of FDG PET-CT scans performed for other diagnostic purposes suggests that BAT is present only in a minority of adults the true prevalence is probably significantly higher.

The activity of BAT is highly variable and, among other factors, dependent on outdoor temperature at the time of diagnostic imaging (Cypess et al., 2009; Saito et al., 2009; Ouellet et al., 2011). Moreover, radiologists had noted bilateral symmetric glucose uptake in FDG PET scans since the early 1990s. As, understandably, such "artifacts" interfered with the main intention of the diagnostic studies (predominantly detection of tumor and metastases), they tried to suppress this unwanted PET tracer uptake by using pre-medication with beta blockers, benzodiazepines and by 
Table 2 | Recent studies on BAT in humans, sorted by study type.

\begin{tabular}{|c|c|}
\hline Reference & Study population, characteristics \\
\hline \multicolumn{2}{|c|}{ RETROSPECTIVE ANALYSIS OF FDG PET-CT SCANS PERFORMED FOR RO } \\
\hline $\begin{array}{l}\text { Cypess et al. } \\
\text { (2009) }\end{array}$ & 1972 Patients (3640 consecutive scans) \\
\hline $\begin{array}{l}\text { Jacene et al. } \\
\text { (2011) }\end{array}$ & $\begin{array}{l}908 \text { Patients; } 445 \text { female, } 463 \text { male; mean age } \pm S D \\
58 \pm 15 \text { years }\end{array}$ \\
\hline $\begin{array}{l}\text { Lee et al. } \\
\text { (2010) }\end{array}$ & $\begin{array}{l}2934 \text { Patients; female 1848, male 1086; mean age } 36 \text { years; } \\
\text { age range } 18-87 \text { years }\end{array}$ \\
\hline
\end{tabular}

\section{Pfannenberg} et al. (2010)

3604 Patients screened, 260 patients analyzed; 98 BAT positive, 162 study-date matched control subjects; 136 female, 124 male; mean age $\pm \mathrm{SE}, 48 \pm 1$ years; age range $11-82$ years; mean BMI $24.5 \pm 0.3 \mathrm{~kg} / \mathrm{m}^{2}$

Gilsanz et al. $\quad 71$ Children and adolescents; 26 female, 45 male; age range (2011) 6-20years

Ouellet et al. (2011)

4842 Patients; 2370 female, 2472 male; mean age \pm SE, $62 \pm 0.2$ years; age range $2-94$ years

Yilmaz et al.
(2011)

3666 Consecutive scans in 1832 patients screened; 30 patients positive for BAT, 90 age and sex matched controls
Main findings

\section{prevalent among patients negative for active BAT. \\ PROSPECTIVE STUDIES USING FDG PET-CT AND COLD EXPOSURE PROTOCOLS IN HEALTHY VOLUNTEERS}

Saito et al. $\quad 56$ Healthy volunteers; 25 female, 31 male; 23-65years of (2009) age
FDG PET positive BAT in 76 of 1013 women (7.5\%) and 30 of 959 men (3.1\%), inverse correlation of BAT activity with age, beta-blocker use, and BMl among older patients.

FDG PET positive BAT in 56 of 908 patients (6.2\%), patients without active BAT had higher risk for hyperglycemia in univariate analysis.

Active BAT identified in 250 patients (8.5\%); 145 patients scanned more than once, showing a high intra-individual variability of BAT activity.

Active BAT associated with female sex. Inversely associated with age, $\mathrm{BMI}$, and fasting glucose.

BAT activity was associated with female sex; inverse correlation of BAT activity with age in men but not in women; inverse correlation with BMI.

30 of 71 children displayed active BAT (42\%); prevalence of active BAT was positively correlated with muscle volume. No differences in age, BMI, or sex were detected.

328 of 4842 patients with active BAT. Prevalence of active BAT was negatively associated with BMI, diabetes mellitus, outdoor temperature, and BMI. Men were less likely than women to display active BAT.

30 of 1832 patients (10 male, 20 female) displayed active BAT (prevalence $2 \%$ ); non-alcoholic fatty liver disease was significantly more Upon cold exposure active BAT was observed in 17 of 32 subjects aged 23-35years and in 2 of 24 subjects aged 38-65years. Inverse correlation of BAT activity vs. BMI, total and visceral body fat, respectively.

Cold exposure induced FDG uptake in all five subjects; presence of BAT proven by immunohistochemistry and molecular analysis (qRT-PCR) for BAT markers.

BAT activity observed in 23 of 24 subjects (96\%) after cold exposure, but not under conditions of thermoneutrality. BAT activity negatively correlated with $\mathrm{BMI}$ and percentage body fat and positively correlated with basal metabolic rate.

Cold-induced BAT activity detected in 3 out of 15 morbidly obese subjects.

Cold activated BAT detected in $41 \%$ of subjects; inverse correlation of

active BAT with BMI, body fat content, abdominal fat, and age. age \pm SD $32.0 \pm 12.1 ; \mathrm{BMI} 22.1 \pm 3.0 \mathrm{~kg} / \mathrm{m}^{2}$

\section{ANALYSIS OFTISSUE SAMPLES OBTAINED DURING SURGERY INTHE NECK REGION}

Zingaretti et al. 35 Patients; 8 male, 27 female; age range 18-82 years, BMI

(2009)

Lee et al.

(2011b) range $18-37 \mathrm{~kg} / \mathrm{m}^{2}$; thyroid surgery for goiter and papillary carcinoma

Prospective cohort study in 17 patients; underwent preoperative FDG PET/CT for staging of head and neck-malignancies prior to surgery; analysis of BAT markers in cervical fat biopsies compared to subcutaneous WAT
Histologic evidence of BAT in 10 of 35 patients; presence of BAT inversely correlated with $\mathrm{BMI}$ and age.

FDG PET/CT positive for BAT in 3 of the 17 patients. However, molecular markers of BAT could be detected in cervical fat biopsies from both PET positive and PET negative patients.

\section{OTHER STUDIES}

Wang et al.

(2011)
FDG PET/CT in 14 patients with pheochromocytoma; 14 matched healthy controls
BAT activity as assessed by FDG PET correlated with total plasma metanephrine. 
warming up to a comfortable room temperature before injecting the tracer substance (Christensen et al., 2006; Soderlund et al., 2007).

Studies specifically designed to detect BAT indicate a much higher prevalence in adult humans. Van Marken Lichtenbelt et al. (2009) used a specific cold stimulation protocol prior to FDG PET scanning and were able to detect active BAT in 23 out of 24 healthy male subjects (96\%). Using a different approach Lee et al. examined 17 patients that underwent staging for head and neck malignancy. While only 3 of 17 had indications of BAT in the FDG PET-CT scan molecular analysis of samples taken from the supraclavicular fat revealed the presence of molecular markers of BAT (UCP1, PRDM16) in all subjects (Lee et al., 2011b). Of the 2934 patients examined with FDG PET-CT in a large Australian study 145 were scanned more than once. The probability to identify active BAT in an individual increased considerably with the number of scans, allowing the authors to estimate the true prevalence of BAT in their cohort to be $64 \%$ (Lee et al., 2010).

\section{ASSOCIATION OF ACTIVE BAT AND OBESITY IN HUMANS}

While the body of evidence is far from being as robust as in rodents, several studies also link the activity of BAT in humans to obesity and associated diseases.

Studies using retrospective analysis of routine FDG PET-CT scans identified a negative correlation of BAT activity and body mass index (BMI) in humans (Cypess et al., 2009; Lee et al., 2010; Pfannenberg et al., 2010; Ouellet et al., 2011). The results of these publications are corroborated by two trials in healthy volunteers that underwent FDG PET-CT scanning after cold exposure to activate BAT (Saito et al., 2009; Van Marken Lichtenbelt et al., 2009). Zingaretti et al. (2009) observed similar results when studying the presence of brown adipocytes in samples of adipose tissue collected in the cervical region of 35 patients undergoing thyroid surgery. Remarkably, active BAT was present in only 3 out of 15 morbidly obese subjects (mean BMI $42.1 \mathrm{~kg} / \mathrm{m}^{2}$ ) upon cold stimulation as assessed with FDG PET-CT (Vijgen et al., 2011). However, the presence of active BAT in $20 \%$ of the subjects indicates that BAT activation might be a possible therapeutic intervention in at least a part of morbidly obese patients.

The prevalence of PET positive BAT seems to decrease with age, as assessed both in retrospective observational studies (Cypess et al., 2009; Pfannenberg et al., 2010; Ouellet et al., 2011) and in prospective studies in healthy volunteers (Saito et al., 2009; Yoneshiro et al., 2011). The declining presence of active BAT with age might be one explanation for the increase of overweight and obesity with age.

In retrospective PET studies the prevalence and activity of BAT was unanimously higher in women than in men (Cypess et al., 2009; Ouellet et al., 2011). Evaluating the FDG PET-CT scans of 260 subjects, 98 of which displayed active BAT, Pfannenberg et al. (2010) described that while in male subjects BAT activity and mass declined with age, this was not the case in female subjects.

Although there are currently no studies prospectively addressing the question, whether active BAT might protect against insulin resistance and diabetes, there is indirect evidence from retrospective cross-sectional studies of patients that underwent FDG PET-CT. Using routine scans Jacene et al. (2011) investigated, whether the presence of active BAT was predictive of elevated fasting glucose levels at the time of the examination. Of the 908 patients $6.2 \%$ had FDG uptake in BAT and in the univariate analysis patients without active BAT had a significantly increased risk to have a blood glucose level of more than $100 \mathrm{mg} / \mathrm{dl}$ ( $>5.6 \mathrm{mmol} / \mathrm{l})$. After adjusting for age, BMI, and sex this difference was not statistically significant. In a larger Australian cohort with 2934 patients, 250 of which displayed active BAT in FDG PET-CT, a significant correlation between fasting glucose and BAT activity was observed. The authors also analyzed data from patients who had been studied repeatedly at different time points and observed an inverse correlation of blood glucose levels and BAT activity in this subset (Lee et al., 2010). These findings are in line with another study describing a reduced prevalence of active BAT in patients with known diabetes (Ouellet et al., 2011).

Non-alcoholic fatty liver disease (NAFLD) is a manifestation of the metabolic syndrome with ectopic lipid deposition in the liver. It is often associated with insulin resistance or type II diabetes mellitus, hyperlipidemia, and hypertension (Vuppalanchi and Chalasani, 2009). In another retrospective evaluation of FDG PET-CT data the presence of active BAT in adults was independently associated with a lower likelihood of NAFLD (Yilmaz et al., 2011).

Recently, Gilsanz et al. published results of a retrospective analysis of FDG PET-CT scans performed in 71 children and adolescents. As expected, the overall prevalence of active BAT was higher $(42 \%)$ than in an adult population. Intriguingly, an association of BAT activity and muscle mass was observed. Contrary to studies performed in adults, no associations with age, BMI, or adiposity could be detected (Gilsanz et al., 2011). However, a major limitation of this study is - as with most of the studies using FDG PET-CT in adult humans - the fact that the study population consisted only of subjects suffering from neoplastic disease.

In some adult patients suffering from pheochromocytoma, a catecholamine secreting tumor of the adrenal medulla, BAT had been discovered and characterized ultrastructurally and biochemically already in the 1980s (Ricquier et al., 1982). It was speculated that the weight loss seen in many patients suffering from pheochromocytoma was due to the activation or recruitment of BAT through high levels of catecholamines (Lean et al., 1986). Not unexpectedly, a more recent study was able to describe a significant correlation of plasma catecholamine levels and BAT activity in patients with pheochromocytoma (Wang et al., 2011).

Correspondingly, the use of beta blockers was inversely correlated to the presence of active BAT in a retrospective, crosssectional study with FDG PET-CT (Cypess et al., 2009). In a controlled prospective trial using cold exposure to activate adaptive thermogenesis, however, administration of the $\beta$ adrenoreceptor antagonist propranolol led to suppression of cold-induced thermogenesis in muscle (presumably $\beta 2 \mathrm{AR}$ mediated) but did not alter cold-induced thermogenesis in BAT (presumably $\beta 3$ mediated; Wijers et al., 2011).

Additionally, the pre-treatment with diazepam - a common practice meant to suppress FDG uptake of BAT during PET scanning - did not result in reduced BAT activity in a randomized controlled trial (Sturkenboom et al., 2009). 


\section{PHARMACOLOGICAL TARGETING OF THERMOGENESIS AND} BAT

A calculation performed on the basis of glucose uptake and estimated usage of fatty acids in BAT of healthy individuals yielded the result that full activation of the present BAT would lead to a potential consumption of $4.1 \mathrm{~kg}$ of adipose tissue over the course of a year (Virtanen et al., 2009). Increasing thermogenesis pharmacologically could therefore provide a promising approach to prevent weight gain and facilitate weight loss in humans.

\section{PHARMACOLOGIC ACTIVATION OF THERMOGENESIS}

About eight decades ago 2,4-dinitrophenol (DNP), an artificial uncoupler of mitochondrial respiration, was used to induce weight loss in humans. It is a small lipophilic molecule that acts as a protonophore, as it can carry protons across membranes (Berg et al., 2007).

The substance was introduced as a drug for weight reduction in the 1930s and a series of studies demonstrated it to cause increased metabolic rate and considerable weight loss without dietary restriction. Since nitrogen excretion remained stable upon treatment with DNP, it was assumed that weight loss was due to fat loss and that muscle was spared. The efficacy of the substance led to a widespread use even as non-prescription drug. Due to the narrow therapeutic range of DNP several cases of fatal hyperthermia occurred, but given the large number of patients who had taken it (more than 100,000 by 1934), the number of severe adverse events was remarkably low. In 1935 several cases of cataract were reported in women taking DNP, which finally resulted in its withdrawal from the market in 1938 (Harper et al., 2001). DNP does of course not selectively uncouple BAT mitochondria, but it nevertheless provides an important proof of principle, as it demonstrates the efficacy of mitochondrial uncoupling for weight loss in humans.

Central stimulation of BAT via the SNS is believed to contribute to the weight reducing effect of sibutramine (Liu et al., 2002). A popular "herbal" weight loss drug, ephedrine, also increases SNS activity and activates BAT, thereby increasing oxygen consumption and thermogenesis (Dulloo et al., 1991; Baba et al., 2007). Yet, stimulation of the SNS can lead to adverse effects such as tachycardia, hypertension, and cardiac arrhythmias, all of which are highly undesirable, especially in obese patients already suffering from cardiovascular disease.

A more selective activation of BAT could be achieved through $\beta 3$-AR agonists. In fact, this strategy has been shown to be effective in rodents (Nagase et al., 1996; Ghorbani and Himms-Hagen, 1997; Umekawa et al., 1997). The orally available selective $\beta 3$ AR agonist L-796568 acutely increased energy expenditure and lipolysis in obese men (Van Baak et al., 2002), but no effects on thermogenesis or body fat were observed after extended treatment over 28 days, probably due to $\beta 3$-AR down-regulation (tachyphylaxis; Larsen et al., 2002). Another study in young, lean men demonstrated increased insulin sensitivity and fat oxidation after 8 weeks of treatment with the $\beta 3$-AR agonist CL316,243, while 24 h-energy expenditure and body weight after 8 weeks remained unchanged as compared to baseline (Weyer et al., 1998).

It must be noted that these studies measured energy expenditure to assess the activation of adaptive thermogenesis. Using FDG PET-CT to visualize BAT activity could possibly detect smaller changes induced by $\beta 3$-AR agonists and should therefore be used for future trials testing similar compounds.

The thermogenic effect of thyroid hormones is well known. Not surprisingly levothyroxine and triiodothyronine have been used to facilitate weight loss in obese patients. Unfortunately, administration of excess thyroid hormone results in overt hyperthyroidism, a condition associated with increased BMR, tachycardia, atrial arrhythmia, muscle wasting, and osteoporosis. The CNS effects of excess thyroid hormone include increased irritability, nervousness, and anxiety (Baxter and Webb, 2009). However, the effects of thyroid hormones are mediated by different isoforms of the THR in a tissue specific fashion. THR $\alpha$ conveys most of the effects on bone development, cardiac gene expression, heart rate, and catecholamine potentiation, while activation of THR $\beta 1$ in mice increased UCP1 expression in BAT (Melmed and Conn, 2005; Ribeiro et al., 2010). Accordingly, the thyroid hormone mimetics GC-1 and KB141, which are selective for THR $\beta 1$, reduced diet induced obesity and normalized serum lipids via increased metabolic rate while not affecting heart rate (Grover et al., 2003, 2004; Villicev et al., 2007). In diabetic ob/ob mice KB141 improved glucose tolerance and insulin sensitivity (Bryzgalova et al., 2008). Thus selective thyroid hormone mimetics might also be of therapeutic benefit in humans.

Activation of the G-protein coupled receptor TGR5 by bile acids increased the expression of DIO2 in BAT and resulted in increased energy expenditure and reduced body weight in mice (Watanabe et al., 2006). Stimulation of DIO2 expression in BAT is particularly interesting as this approach increases triiodothyronine availability locally but not systemically thus obviating the deleterious effects of hyperthyroidism. The co-expression of TGR5 and DIO2 in BAT makes bile acids and derived compounds promising drug candidates for the activation of thermogenesis.

\section{EXPANSION OF BROWN ADIPOSE TISSUE}

As outlined above, the prevalence of active BAT, as determined by FDG PET-CT, is lower in overweight and obese subjects than in lean controls. To make use of the energy dissipating effect of BAT in obese persons, it might thus be necessary to expand the amount of BAT. Recently, brown adipocyte progenitors that could be differentiated into UCP1 expressing cells in vitro have been discovered in human WAT (Elabd et al., 2009). Additionally, Lee et al. obtained fat biopsies from the supraclavicular fossa guided by PET-CT. They were able to differentiate brown adipocyte precursors to UCP1 expressing brown adipocytes, regardless whether PET analysis had shown active BAT or not (Lee et al., 2011a). These findings provide a rationale for therapeutic expansion of BAT in humans.

In rodents several small molecules and hormones have been found to promote the expansion of BAT. Fibroblast growth factors (FGF) are a family of polypeptide growth factors that regulate cell proliferation, migration, and differentiation during embryonic development and function as homeostatic factors in tissue repair and response to injury in the adult organism (Ornitz and Itoh, 2001). Several members of the family have been implied in BAT physiology.

Cold exposure induces the expression of basic fibroblast growth factor $(\mathrm{bFGF}=\mathrm{FGF}-2)$ in BAT and this growth factor seems to 
stimulate BAT growth through autocrine feedback (Yamashita et al., 1994; Asano et al., 1999).

While FGF-16 mainly seems to be responsible for growth of BAT during embryonic development (Konishi et al., 2000), FGF19 and FGF-21 demonstrated effects on thermogenesis in adult mice. Intra-cerebroventricular administration of FGF-19 in mice increased metabolic rate, prevented diet induced obesity and improved insulin sensitivity (Fu et al., 2004). It is an especially attractive molecule since it specifically binds to FGF-receptor 4 and does not appear to be mitogenic.

In newborn mice FGF-21 expression in the liver is reduced in response to fasting and induced by suckling via PPAR $\alpha$ dependent mechanisms. Injection of FGF-21 into newborn fasting mice induced genes involved in thermogenesis in BAT and increased body temperature. In vitro FGF-21 induced expression of thermogenic genes and increased total and uncoupled respiration (Hondares et al., 2010). Interestingly, FGF-21 expression is induced in BAT itself by cold exposure or adrenergic stimulation via $\beta$ adrenergic pathways (Chartoumpekis et al., 2011; Hondares et al., 2011).

Fibroblast growth factors are attractive from a pharmacological point of view: like other peptides they might be produced recombinantly or substituted by small molecules that specifically activate FGF receptors and could easily be produced in large scale.

BMP-7, a member of the TGF- $\beta$ superfamily was originally identified as a bone inducer, but recent evidence suggests an important role in brown fat development as well. BMP-7 can activate the full program of brown fat differentiation both in vitro and in vivo. Tseng et al. (2008) injected mice with hepatotropic adenoviruses expressing BMP-7 resulting in hepatic overexpression and secretion of the protein. In comparison to control mice those injected with the BMP-7 expressing retroviruses showed increased thermogenesis, higher body temperature and reduced body weight.

An alternative strategy could be to transdifferentiate adipocyte precursors obtained from liposuction into brown adipocytes ex vivo and then re-transplant the thermogenically active cells. This could be achieved through overexpression of PRDM16, FOXC2, or PGC-1 $\alpha$ in the cells. Compared to a conventional pharmacological approach, however, such a method would be elaborate and expensive and questions of optimal location for implantation, of blood supply and of innervation remain to be solved.

Currently, FDG PET-CT is the sole imaging modality to investigate BAT activity directly. This is a major obstacle in the investigation of BAT activity and potential pharmaceuticals that increase

\section{REFERENCES}

Adams, T. D., Gress, R. E., Smith, S. C., Halverson, R. C., Simper, S. C., Rosamond, W. D., Lamonte, M. J., Stroup, A. M., and Hunt, S. C. (2007). Long-term mortality after gastric bypass surgery. N. Engl. J. Med. 357, 753-761.

Asano, A., Kimura, K., and Saito, M. (1999). Cold-induced mRNA expression of angiogenic factors in rat brown adipose tissue. J. Vet. Med. Sci. 61, 403-409.

Atit, R., Sgaier, S. K., Mohamed, O. A., Taketo, M. M., Dufort, D., Joyner, A. L., Niswander, L., and Conlon, R. A. (2006). Beta-catenin activation is necessary and sufficient to specify the dorsal dermal fate in the mouse. Dev. Biol. 296, 164-176.

Baba, S., Tatsumi, M., Ishimori, T., Lilien, D. L., Engles, J. M., and Wahl,

BAT activity. Recent developments in nuclear magnetic resonance imaging (MRI; Hu et al., 2010; Branca and Warren, 2011) could facilitate the evaluation of BAT activity without exposure to ionizing radiation thus giving the research in the field an enormous boost.

Apart from the search for drugs that increase BAT thermogenesis, it will also be important to further investigate the consequences of thermoneutrality and cold exposure. Humans in the developed world spend most of their time in a thermoneutral zone maintained by advanced heating systems and protective clothing (Van Marken Lichtenbelt and Schrauwen, 2011). As BAT is activated by sensing cold long prior to a drop of core temperature and at ambient temperatures around $16^{\circ} \mathrm{C}$, deliberately lowering ambient temperatures in buildings could be a feasible approach to increase BAT activity and to prevent obesity.

\section{CONCLUSION}

Given the growing world-wide prevalence and increasing burden of obesity and associated diseases and the current lack of effective treatment strategies, new therapeutic approaches in the field of anti-obesity therapies are clearly needed.

During the recent years our knowledge of BAT physiology and development and its implications in metabolic disease has increased dramatically. Most importantly, there is robust evidence that BAT is present in a majority of human adults. Furthermore, a growing body of literature indicates that active BAT is inversely associated with obesity and metabolic disease. In rodent models several pharmacological approaches which increase BAT activity, have been proven to effectively prevent obesity, facilitate weight reduction, and ameliorate insulin resistance. Deducing from the animal model these approaches might work in humans as well.

Many questions regarding therapeutic activation or expansion of BAT remain to be solved. It is yet unclear how effective an increase of thermogenesis would be to reduce obesity and ameliorate insulin resistance. Compensating mechanisms, such as increased appetite, could reduce the benefits of this approach. Not least, the infamous history of the uncoupling agent DNP reminds us to pay close attention to contingent risks of drugs that activate thermogenesis. Considering the disappointing results of pharmacological approaches targeting energy intake and appetite, stimulation of BAT activity and increasing energy expenditure would provide exciting new options in obesity therapy.

\section{ACKNOWLEDGMENTS}

The authors would like to thank Martin E. Lidell and Mikael Heglind for critical review of the manuscript.

R. L. (2007). Effect of nicotine and ephedrine on the accumulation of 18F-FDG in brown adipose tissue. J. Nucl. Med. 48, 981-986.

Bartelt, A., Bruns, O. T., Reimer, R., Hohenberg, H., Ittrich, H., Peldschus, K., Kaul, M. G., Tromsdorf, U. I., Weller, H., Waurisch, C., Eychmuller, A., Gordts, P. L., Rinninger, F., Bruegelmann, K., Freund, B., Nielsen, P., Merkel, M., and Heeren,
J. (2011). Brown adipose tissue activity controls triglyceride clearance. Nat. Med. 17, 200-205.

Baxter, J. D., and Webb, P. (2009). Thyroid hormone mimetics: potential applications in atherosclerosis, obesity and type 2 diabetes. Nat. Rev. Drug Discov. 8, 308-320.

Berg, J. M., Tymoczko, J. L., and Stryer, L. (2007). Biochemistry. New York, NY: W. H. Freeman. 
Berrington De Gonzalez, A., Hartge, P., Cerhan, J. R., Flint, A. J., Hannan, L., Macinnis, R. J., Moore, S. C., Tobias, G. S., Anton-Culver, H., Freeman, L. B., Beeson, W. L., Clipp, S. L., English, D. R., Folsom, A. R., Freedman, D. M., Giles, G., Hakansson, N., Henderson, K. D., Hoffman-Bolton, J., Hoppin, J. A., Koenig, K. L., Lee, I.M., Linet, M. S., Park, Y., Pocobelli, G., Schatzkin, A., Sesso, H. D., Weiderpass, E., Willcox, B. J., Wolk, A., Zeleniuch-Jacquotte, A., Willett, W. C., and Thun, M. J. (2010). Bodymass index and mortality among 1.46 million white adults. N. Engl. J. Med. 363, 2211-2219.

Bianco, A. C., and Kim, B. W. (2006). Deiodinases: implications of the local control of thyroid hormone action. J. Clin. Invest. 116, 2571-2579.

Branca, R. T., and Warren, W. S. (2011). In vivo brown adipose tissue detection and characterization using water-lipid intermolecular zero-quantum coherences. Magn. Reson. Med. 65, 313-319.

Bryzgalova, G., Effendic, S., Khan, A., Rehnmark, S., Barbounis, P., Boulet, J., Dong, G., Singh, R., Shapses, S., Malm, J., Webb, P., Baxter, J. D., and Grover, G. J. (2008). Antiobesity, anti-diabetic, and lipid lowering effects of the thyroid receptor beta subtype selective agonist KB141. J. Steroid Biochem. Mol. Biol. 111, 262-267.

Cannon, B., and Nedergaard, J. (2004). Brown adipose tissue: function and physiological significance. Physiol. Rev. 84, 277-359.

Cederberg, A., Gronning, L. M., Ahren, B., Tasken, K., Carlsson, P., and Enerback, S. (2001). FOXC2 is a winged helix gene that counteracts obesity, hypertriglyceridemia, and dietinduced insulin resistance. Cell 106, 563-573.

Chartoumpekis, D. V., Habeos, I. G., Ziros, P. G., Psyrogiannis, A. I., Kyriazopoulou, V. E., and Papavassiliou, A. G. (2011). Brown adipose tissue responds to cold and adrenergic stimulation by induction of FGF21. Mol. Med. 17, 736-740.

Christensen, C. R., Clark, P. B., and Morton, K. A. (2006). Reversal of hypermetabolic brown adipose tissue in F-18 FDG PET imaging. Clin. Nucl. Med. 31, 193-196.

Christensen, R., Kristensen, P. K., Bartels, E. M., Bliddal, H., and Astrup, A. (2007). Efficacy and safety of the weight-loss drug rimonabant: a meta-analysis of randomised trials. Lancet 370, 1706-1713.

Collins, S., Daniel, K. W., Petro, A. E., and Surwit, R. S. (1997).
Strain-specific response to $\beta 3$ adrenergic receptor agonist treatment of diet-induced obesity in mice. Endocrinology 138, 405-413.

Cypess, A. M., Lehman, S., Williams, G., Tal, I., Rodman, D., Goldfine, A. B., Kuo, F. C., Palmer, E. L., Tseng, Y. H., Doria, A., Kolodny, G. M., and Kahn, C. R. (2009). Identification and importance of brown adipose tissue in adult humans. N. Engl. J. Med. 360, 1509-1517.

Dahle, M. K., Gronning, L. M., Cederberg, A., Blomhoff, H. K., Miura, N., Enerback, S., Tasken, K. A., and Tasken, K. (2002). Mechanisms of FOXC2- and FOXD1mediated regulation of the RI alpha subunit of cAMP-dependent protein kinase include release of transcriptional repression and activation by protein kinase $\mathrm{B}$ alpha and cAMP. J. Biol. Chem. 277, 22902-22908.

Dulloo, A. G., Jacquet, J., and Girardier, L. (1997). Poststarvation hyperphagia and body fat overshooting in humans: a role for feedback signals from lean and fat tissues. Am. J. Clin. Nutr. 65, 717-723.

Dulloo, A. G., and Miller, D. S. (1984). Energy balance following sympathetic denervation of brown adipose tissue. Can. J. Physiol. Pharmacol.62, 235-240.

Dulloo, A. G., Seydoux, J., and Girardier, L. (1991). Peripheral mechanisms of thermogenesis induced by ephedrine and caffeine in brown adipose tissue. Int. J. Obes. 15, 317-326.

Eckel, R. H. (2008). Clinical practice. Nonsurgical management of obesity in adults. N. Engl. J. Med. 358, 1941-1950.

Elabd, C., Chiellini, C., Carmona, M., Galitzky, J., Cochet, O., Petersen, R., Penicaud, L., Kristiansen, K., Bouloumie, A., Casteilla, L., Dani, C., Ailhaud, G., and Amri, E. Z. (2009). Human multipotent adiposederived stem cells differentiate into functional brown adipocytes. Stem Cells 27, 2753-2760.

Enerback, S., Jacobsson, A., Simpson, E. M., Guerra, C., Yamashita, H., Harper, M. E., and Kozak, L. P. (1997). Mice lacking mitochondrial uncoupling protein are coldsensitive but not obese. Nature 387, 90-94.

Feldmann, H. M., Golozoubova, V., Cannon, B., and Nedergaard, J. (2009). UCP1 ablation induces obesity and abolishes diet-induced thermogenesis in mice exempt from thermal stress by living at thermoneutrality. Cell Metab. 9, 203-209.
Fromme, T., and Klingenspor, $\mathrm{M}$. (2011). Uncoupling protein 1 expression and high-fat diets. Am. J. Physiol. Regul. Integr. Comp. Physiol. 300, R1-R8.

Fu, L., John, L. M., Adams, S. H., Yu, X. X., Tomlinson, E., Renz, M., Williams, P. M., Soriano, R., Corpuz, R., Moffat, B., Vandlen, R., Simmons, L., Foster, J., Stephan, J. P., Tsai, S. P., and Stewart, T. A. (2004). Fibroblast growth factor 19 increases metabolic rate and reverses dietary and leptin-deficient diabetes. Endocrinology 145, 2594-2603.

Ghorbani, M., and Himms-Hagen, J. (1997). Appearance of brown adipocytes in white adipose tissue during CL 316,243-induced reversal of obesity and diabetes in Zucker $\mathrm{fa} / \mathrm{fa}$ rats. Int. J. Obes. Relat. Metab. Disord. 21, 465-475.

Gilsanz, V., Chung, S. A., Jackson, H., Dorey, F. J., and Hu, H. H. (2011). Functional brown adipose tissue is related to muscle volume in children and adolescents. J. Pediatr. 158, 722-726.

Goodpaster, B. H., Delany, J. P., Otto, A. D., Kuller, L., Vockley, J., SouthPaul, J. E., Thomas, S. B., Brown, J., Mctigue, K., Hames, K. C. Lang, W., and Jakicic, J. M. (2010). Effects of diet and physical activity interventions on weight loss and cardiometabolic risk factors in severely obese adults. JAMA 304, 1795-1802.

Grover, G. J., Egan, D. M., Sleph, P. G. Beehler, B. C., Chiellini, G., Nguyen, N. H., Baxter, J. D., and Scanlan, T. S. (2004). Effects of the thyroid hormone receptor agonist GC-1 on metabolic rate and cholesterol in rats and primates: selective actions relative to $3,5,3^{\prime}$-triiodo-L-thyronine. Endocrinology 145, 1656-1661.

Grover, G. J., Mellstrom, K., Ye, L., Malm, J., Li, Y. L., Bladh, L. G., Sleph, P. G., Smith, M. A., George, R., Vennstrom, B., Mookhtiar, K. Horvath, R., Speelman, J., Egan, D. and Baxter, J. D. (2003). Selective thyroid hormone receptor-beta activation: a strategy for reduction of weight, cholesterol, and lipoprotein (a) with reduced cardiovascular liability. Proc. Natl. Acad. Sci. U.S.A. 100, 10067-10072.

Guerra, C., Koza, R. A., Yamashita, H., Walsh, K., and Kozak, L. P. (1998). Emergence of brown adipocytes in white fat in mice is under genetic control. Effects on body weight and adiposity. J. Clin. Invest. 102, 412-420.

Harper, J. A., Dickinson, K., and Brand, M. D. (2001). Mitochondrial uncoupling as a target for drug development for the treatment of obesity. Obes. Rev. 2, 255-265.

Haslam, D. W., and James, W. P. (2005). Obesity. Lancet 366, 1197-1209.

Hondares, E., Iglesias, R., Giralt, A., Gonzalez, F. J., Giralt, M., Mampel, T., and Villarroya, F. (2011). Thermogenic activation induces FGF21 expression and release in brown adipose tissue. J. Biol. Chem. 286, 12983-12990.

Hondares, E., Rosell, M., Gonzalez, F. J., Giralt, M., Iglesias, R., and Villarroya, F. (2010). Hepatic FGF21 expression is induced at birth via PPARalpha in response to milk intake and contributes to thermogenic activation of neonatal brown fat. Cell Metab. 11, 206-212.

Hu, H. H., Smith, D. L. Jr., Nayak, K. S., Goran, M. I., and Nagy, T. R. (2010). Identification of brown adipose tissue in mice with fat-water IDEALMRI. J. Magn. Reson. Imaging 31, 1195-1202.

Jacene, H. A., Cohade, C. C., Zhang, Z., and Wahl, R. L. (2011). The relationship between patients' serum glucose levels and metabolically active brown adipose tissue detected by PET/CT. Mol. Imaging Biol. 13, 1278-1283.

James, W. P., Caterson, I. D., Coutinho, W., Finer, N., Van Gaal, L. F., Maggioni, A. P., Torp-Pedersen, C., Sharma, A. M., Shepherd, G. M., Rode, R. A., and Renz, C. L. (2010). Effect of sibutramine on cardiovascular outcomes in overweight and obese subjects. N. Engl. J. Med. 363 , 905-917.

Kershaw, E. E., and Flier, J. S. (2004). Adipose tissue as an endocrine organ. J. Clin. Endocrinol. Metab. 89, 2548-2556.

Kim, J. K., Kim, H. J., Park, S. Y., Cederberg, A., Westergren, R., Nilsson, D., Higashimori, T., Cho, Y. R., Liu, Z. X., Dong, J., Cline, G. W., Enerback, S., and Shulman, G. I. (2005). Adipocyte-specific overexpression of FOXC2 prevents dietinduced increases in intramuscular fatty acyl CoA and insulin resistance. Diabetes 54, 1657-1663.

Konishi, M., Mikami, T., Yamasaki, M., Miyake, A., and Itoh, N. (2000). Fibroblast growth factor-16 is a growth factor for embryonic brown adipocytes. J. Biol. Chem. 275, 12119-12122.

Kopecky, J., Clarke, G., Enerback, S., Spiegelman, B., and Kozak, L. P. (1995). Expression of the mitochondrial uncoupling protein gene from the aP2 gene promoter prevents genetic obesity. J. Clin. Invest. 96, 2914-2923. 
Kozak, L. P. (2010). Brown fat and the myth of diet-induced thermogenesis. Cell Metab. 11, 263-267.

Larsen, T. M., Toubro, S., Van Baak, M. A., Gottesdiener, K. M., Larson, P., Saris, W. H., and Astrup, A. (2002). Effect of a 28-d treatment with L796568, a novel beta(3)-adrenergic receptor agonist, on energy expenditure and body composition in obese men. Am. J. Clin. Nutr. 76, 780-788.

Lean, M. E., James, W. P., Jennings, G., and Trayhurn, P. (1986). Brown adipose tissue in patients with phaeochromocytoma. Int. J. Obes. 10, 219-227.

Lee, P., Greenfield, J. R., Ho, K. K., and Fulham, M. J. (2010). A critical appraisal of the prevalence and metabolic significance of brown adipose tissue in adult humans. Am. J. Physiol. Endocrinol. Metab. 299, E601-E606

Lee, P., Swarbrick, M. M., Zhao, J. T., and Ho, K. K. (2011a). Inducible brown adipogenesis of supraclavicular fat in adult humans. Endocrinology 152, 3597-3602.

Lee, P., Zhao, J. T., Swarbrick, M. M., Gracie, G., Bova, R., Greenfield, J. R., Freund, J., and Ho, K. K. (2011b). High prevalence of brown adipose tissue in adult humans. J. Clin. Endocrinol. Metab. 96, 2450-2455.

Liu, Y. L., Heal, D. J., and Stock, M. J. (2002). Mechanism of the thermogenic effect of metabolite 2 (BTS 54 505), a major pharmacologically active metabolite of the novel anti-obesity drug, sibutramine. Int. J. Obes. Relat. Metab. Dis. 26, 1245-1253.

Lowell, B. B., V, S. S., Hamann, A., Lawitts, J. A., Himms-Hagen, J., Boyer, B. B., Kozak, L. P., and Flier, J. S. (1993). Development of obesity in transgenic mice after genetic ablation of brown adipose tissue. Nature $366,740-742$.

Martin, C. K., Heilbronn, L. K., De Jonge, L., Delany, J. P., Volaufova, J., Anton, S. D., Redman, L. M., Smith, S. R., and Ravussin, E. (2007). Effect of calorie restriction on resting metabolic rate and spontaneous physical activity. Obesity (Silver Spring) 15, 2964-2973.

Melmed, S., and Conn, P. M. (eds). (2005). Endocrinology: Basic and Clinical Principles. Totowa, NJ: Humana Press.

Nagase, I., Yoshida, T., Kumamoto, K., Umekawa, T., Sakane, N., Nikami, H., Kawada, T., and Saito, M. (1996). Expression of uncoupling protein in skeletal muscle and white fat of obese mice treated with thermogenic beta 3-adrenergic agonist. J. Clin. Invest. 97, 2898-2904.
Nakamura, K., and Morrison, S. F. (2007). Central efferent pathways mediating skin cooling-evoked sympathetic thermogenesis in brown adipose tissue. Am. J. Physiol. Regul. Integr. Comp. Physiol. 292, R127R136.

Ornitz, D. M., and Itoh, N. (2001). Fibroblast growth factors. Genome Biol. 2, reviews3005.3001-3005. 3012.

Ouellet, V., Routhier-Labadie, A., Bellemare, W., Lakhal-Chaieb, L., Turcotte, E., Carpentier, A. C., and Richard, D. (2011). Outdoor temperature, age, sex, body mass index, and diabetic status determine the prevalence, mass, and glucoseuptake activity of 18F-FDG-detected BAT in humans. J. Clin. Endocrinol. Metab. 96, 192-199.

Petersen, K. F., Dufour, S., Befroy, D., Lehrke, M., Hendler, R. E., and Shulman, G. I. (2005). Reversal of nonalcoholic hepatic steatosis, hepatic insulin resistance, and hyperglycemia by moderate weight reduction in patients with type 2 diabetes. Diabetes 54, 603-608.

Pfannenberg, C., Werner, M. K., Ripkens, S., Stef, I., Deckert, A., Schmadl, M., Reimold, M., Haring, H. U., Claussen, C. D., and Stefan, N. (2010). Impact of age on the relationships of brown adipose tissue with sex and adiposity in humans. Diabetes 59, 1789-1793.

Pischon, T., Boeing, H., Hoffmann, K., Bergmann, M., Schulze, M. B., Overvad, K., Van Der Schouw, Y. T., Spencer, E., Moons, K. G. M., Tjønneland, A., Halkjaer, J., Jensen, M. K., Stegger, J., Clavel-Chapelon, F., Boutron-Ruault, M.-C., Chajes, V., Linseisen, J., Kaaks, R., Trichopoulou, A., Trichopoulos, D., Bamia, C., Sieri, S., Palli, D., Tumino, R., Vineis, P., Panico, S., Peeters, P. H. M., May, A. M., Bueno-De-Mesquita, H. B., Van Duijnhoven, F. J. B., Hallmans, G., Weinehall, L., Manjer, J., Hedblad, B., Lund, E., Agudo, A., Arriola, L., Barricarte, A., Navarro, C., Martinez, C., Quirós, J. R., Key, T., Bingham, S., Khaw, K. T., Boffetta, P., Jenab, M., Ferrari, P., and Riboli, E. (2008). General and abdominal adiposity and risk of death in Europe. N. Engl. J. Med. 359, 2105-2120.

Qatanani, M., and Lazar, M. A. (2007) Mechanisms of obesity-associated insulin resistance: many choices on the menu. Genes Dev. 21, 1443-1455.

Redman, L. M., Heilbronn, L. K., Martin, C. K., De Jonge, L., Williamson, D. A., Delany, J. P., and Ravussin, E. (2009). Metabolic and behavioral compensations in response to caloric restriction: implications for the maintenance of weight loss. PLoS ONE 4, e4377. doi:10.1371/journal.pone. 0004377

Ribeiro, M. O., Bianco, S. D., Kaneshige, M., Schultz, J. J., Cheng, S. Y., Bianco, A. C., and Brent, G. A. (2010). Expression of uncoupling protein 1 in mouse brown adipose tissue is thyroid hormone receptor-beta isoform specific and required for adaptive thermogenesis. Endocrinology 151, 432-440.

Ricquier, D., Nechad, M., and Mory, G. (1982). Ultrastructural and biochemical characterization of human brown adipose tissue in pheochromocytoma. J. Clin. Endocrinol. Metab. 54, 803-807.

Rothwell, N. J., and Stock, M. J. (1979). A role for brown adipose tissue in diet-induced thermogenesis. Nature 281, 31-35.

Saito, M., Okamatsu-Ogura, Y., Matsushita, M., Watanabe, K., Yoneshiro, T., Nio-Kobayashi, J., Iwanaga, T., Miyagawa, M., Kameya, T., Nakada, K., Kawai, Y., and Tsujisaki, M. (2009). High incidence of metabolically active brown adipose tissue in healthy adult humans: effects of cold exposure and adiposity. Diabetes 58 1526-1531.

Seale, P., Bjork, B., Yang, W., Kajimura, S., Chin, S., Kuang, S., Scime, A., Devarakonda, S., Conroe, H. M., Erdjument-Bromage, H., Tempst, P., Rudnicki, M. A., Beier, D. R., and Spiegelman, B. M. (2008). PRDM16 controls a brown fat/skeletal muscle switch. Nature 454, 961-967.

Seale, P., Conroe, H. M., Estall, J., Kajimura, S., Frontini, A., Ishibashi, J., Cohen, P., Cinti, S., and Spiegelman, B. M. (2011). Prdm16 determines the thermogenic program of subcutaneous white adipose tissue in mice. J. Clin. Invest. 121, 96-105.

Seale, P., Kajimura, S., and Spiegelman, B. M. (2009). Transcriptional control of brown adipocyte development and physiological function of mice and men. Genes Dev. 23, 788-797.

Silva, J. E., and Rabelo, R. (1997). Regulation of the uncoupling protein gene expression. Eur. J. Endocrinol. 136, 251-264.

Sjostrom, L., Lindroos, A. K., Peltonen, M., Torgerson, J., Bouchard C., Carlsson, B., Dahlgren, S., Larsson, B., Narbro, K., Sjostrom, C. D., Sullivan, M., and Wedel, $\mathrm{H}$. (2004). Lifestyle, diabetes, and cardiovascular risk factors 10 years after bariatric surgery. N. Engl. J. Med. 351, 2683-2693.

Sjostrom, L., Narbro, K., Sjostrom, C. D., Karason, K., Larsson, B. Wedel, H., Lystig, T., Sullivan, M.,
Bouchard, C., Carlsson, B., Bengtsson, C., Dahlgren, S., Gummesson, A., Jacobson, P., Karlsson, J., Lindroos, A. K., Lonroth, H., Naslund, I., Olbers, T., Stenlof, K., Torgerson, J., Agren, G., and Carlsson, L. M. (2007). Effects of bariatric surgery on mortality in Swedish obese subjects. N. Engl. J. Med. 357, 741-752.

Soderlund, V., Larsson, S. A., and Jacobsson, H. (2007). Reduction of FDG uptake in brown adipose tissue in clinical patients by a single dose of propranolol. Eur. J. Nucl. Med. Mol. Imaging 34, 1018-1022.

Sturkenboom, M. G., Hoekstra, O. S., Postema, E. J., Zijlstra, J. M., Berkhof, J., and Franssen, E. J. (2009). A randomised controlled trial assessing the effect of oral diazepam on 18FFDG uptake in the neck and upper chest region. Mol. Imaging Biol. 11, 364-368.

Timmons, J. A., Wennmalm, K., Larsson, O., Walden, T. B., Lassmann, T., Petrovic, N., Hamilton, D. L., Gimeno, R. E., Wahlestedt, C., Baar, K., Nedergaard, J., and Cannon, B. (2007). Myogenic gene expression signature establishes that brown and white adipocytes originate from distinct cell lineages. Proc. Natl. Acad. Sci. U.S.A. 104, 4401-4406.

Tseng, Y. H., Kokkotou, E., Schulz, T. J., Huang, T. L., Winnay, J. N., Taniguchi, C. M., Tran, T. T., Suzuki, R., Espinoza, D. O., Yamamoto, Y., Ahrens, M. J., Dudley, A. T., Norris, A. W., Kulkarni, R. N., and Kahn, C. R. (2008). New role of bone morphogenetic protein 7 in brown adipogenesis and energy expenditure. Nature 454, 1000-1004.

Umekawa, T., Yoshida, T., Sakane, N., Saito, M., Kumamoto, K., and Kondo, M. (1997). Anti-obesity and anti-diabetic effects of CL316,243, a highly specific beta 3 -adrenoceptor agonist, in Otsuka Long-Evans Tokushima Fatty rats: induction of uncoupling protein and activation of glucose transporter 4 in white fat. Eur. J. Endocrinol. 136, 429-437.

Van Baak, M. A., Hul, G. B., Toubro, S., Astrup, A., Gottesdiener, K. M., Desmet, M., and Saris, W. H. (2002). Acute effect of L-796568, a novel beta 3-adrenergic receptor agonist, on energy expenditure in obese men. Clin. Pharmacol. Ther. 71, 272-279.

Van Marken Lichtenbelt, W. D., and Schrauwen, P. (2011). Implications of nonshivering thermogenesis for energy balance regulation in humans. Am. J. Physiol. Regul. Integr. Comp. Physiol. 301, R285-R296. 
Van Marken Lichtenbelt, W. D., Vanhommerig, J. W., Smulders, N. M., Drossaerts, J. M., Kemerink, G. J., Bouvy, N. D., Schrauwen, P., and Teule, G. J. (2009). Cold-activated brown adipose tissue in healthy men. N. Engl. J. Med. 360, 1500-1508.

Vijgen, G. H., Bouvy, N. D., Teule, G. J., Brans, B., Schrauwen, P., and Van Marken Lichtenbelt, W. D. (2011). Brown adipose tissue in morbidly obese subjects. PLoS ONE 6, el7247. doi:10.1371/journal.pone.0017247

Villicev, C. M., Freitas, F. R., Aoki, M. S., Taffarel, C., Scanlan, T. S., Moriscot, A. S., Ribeiro, M. O., Bianco, A. C., and Gouveia, C. H. (2007). Thyroid hormone receptor beta-specific agonist GC-1 increases energy expenditure and prevents fat-mass accumulation in rats. J. Endocrinol. 193, 21-29.

Virtanen, K. A., Lidell, M. E., Orava, J., Heglind, M., Westergren, R., Niemi, T., Taittonen, M., Laine, J., Savisto, N. J., Enerback, S., and Nuutila, P. (2009). Functional brown adipose tissue in healthy adults. N. Engl. J. Med. 360, 1518-1525.

Vuppalanchi, R., and Chalasani, N. (2009). Nonalcoholic fatty liver disease and nonalcoholic steatohepatitis: selected practical issues in their evaluation and management. Нераtology 49, 306-317.

Wang, Q., Zhang, M., Ning, G., Gu, W., Su, T., Xu, M., Li, B., and Wang, W. (2011). Brown adipose tissue in humans is activated by elevated plasma catecholamines levels and is inversely related to central obesity. PLoS ONE 6, e21006. doi:10.1371/journal.pone.0021006

Watanabe, M., Houten, S. M., Mataki, C., Christoffolete, M. A., Kim, B. W., Sato, H., Messaddeq, N., Harney, J. W., Ezaki, O., Kodama, T., Schoonjans, K., Bianco, A. C., and Auwerx, J. (2006). Bile acids induce energy expenditure by promoting intracellular thyroid hormone activation. Nature 439, 484-489.

Weinsier, R. L., Hunter, G. R., Desmond, R. A., Byrne, N. M., Zuckerman, P. A., and Darnell, B. E. (2002). Free-living activity energy expenditure in women successful and unsuccessful at maintaining a normal body weight. Am. J. Clin. Nutr. 75, 499-504.

Weyer, C., Tataranni, P. A., Snitker, S., Danforth, E. Jr., and Ravussin, E. (1998). Increase in insulin action and fat oxidation after treatment with CL 316,243, a highly selective beta3-adrenoceptor agonist in humans. Diabetes 47, 1555-1561.

Wijers, S. L., Schrauwen, P., Van Baak, M. A., Saris, W. H., and Van Marken Lichtenbelt, W. D. (2011). Betaadrenergic receptor blockade does not inhibit cold-induced thermogenesis in humans: possible involvement of brown adipose tissue. J. Clin. Endocrinol. Metab. 96, E598E605.

Wing, R. R., and Hill, J. O. (2001). Successful weight loss maintenance. Annu. Rev. Nutr. 21, 323-341.

Xue, B., Rim, J. S., Hogan, J. C., Coulter, A. A., Koza, R. A., and Kozak, L. P.
(2007). Genetic variability affects the development of brown adipocytes in white fat but not in interscapular brown fat. J. Lipid Res. 48, 41-51.

Yamashita, H., Sato, Y., Kizaki, T., Oh, S., Nagasawa, J., and Ohno, H. (1994). Basic fibroblast growth factor (bFGF) contributes to the enlargement of brown adipose tissue during cold acclimation. Pflugers Arch. 428, 352-356.

Yilmaz, Y., Ones, T., Purnak, T., Ozguven, S., Kurt, R., Atug, O., Turoglu, H. T., and Imeryuz, N. (2011). Association between the presence of brown adipose tissue and nonalcoholic fatty liver disease in adult humans. Aliment. Pharmacol. Ther. 34, 318-323.

Yoneshiro, T., Aita, S., Matsushita, M. Okamatsu-Ogura, Y., Kameya, T., Kawai, Y., Miyagawa, M., Tsujisaki, M., and Saito, M. (2011). Age-related decrease in cold-activated brown adipose tissue and accumulation of body fat in healthy humans. Obesity (Silver Spring) 19, 1755-1760.

Zheng, W., Mclerran, D. F., Rolland, B., Zhang, X., Inoue, M., Matsuo, K., He, J., Gupta, P. C., Ramadas, K., Tsugane, S., Irie, F., Tamakoshi, A., Gao, Y.-T., Wang, R., Shu, X.-O., Tsuji, I., Kuriyama, S., Tanaka, H., Satoh, H., Chen, C.-J., Yuan, J.-M., Yoo, K.-Y., Ahsan, H., Pan, W.-H., Gu, D., Pednekar, M. S., Sauvaget, C., Sasazuki, S., Sairenchi, T., Yang, G., Xiang, Y.B., Nagai, M., Suzuki, T., Nishino, Y., You, S.-L., Koh, W.-P., Park, S. K., Chen, Y., Shen, C.-Y., Thornquist, M., Feng, Z., Kang, D., Boffetta, P., and Potter, J. D. (2011). Association between body-mass index and risk of death in more than 1 million Asians. N. Engl. J. Med.364, 719-729.

Zingaretti, M. C., Crosta, F., Vitali, A., Guerrieri, M., Frontini, A., Cannon, B., Nedergaard, J., and Cinti, S. (2009). The presence of UCP1 demonstrates that metabolically active adipose tissue in the neck of adult humans truly represents brown adipose tissue. FASEB J. 23, 3113-3120.

Conflict of Interest Statement: The authors declare that the research was conducted in the absence of any commercial or financial relationships that could be construed as a potential conflict of interest.

Received: 29 August 2011; paper pending published: 29 September 2011; accepted: 12 November 2011; published online: 29 November 2011.

Citation: Betz MJ and Enerbäck $S$ (2011) Therapeutic prospects of metabolically active brown adipose tissue in humans. Front. Endocrin. 2:86. doi: 10.3389/fendo.2011.00086

This article was submitted to Frontiers in Cellular Endocrinology, a specialty of Frontiers in Endocrinology.

Copyright (C) 2011 Betz and Enerbäck. This is an open-access article distributed under the terms of the Creative Commons Attribution Non Commercial License, which permits use, distribution, and reproduction in other forums, provided the original authors and source are credited. 